\title{
CONSTRUCTION OF A VECTOR CONTAINING HYGROMYCIN (HPT) GENE DRIVEN BY DOUBLE 35S (2XCAMV35S) PROMOTER FOR OIL PALM TRANSFORMATION
}

\author{
BOHARI BAHARIAH*; MAT YUNUS ABDUL MASANI*; OMAR ABDUL RASID* and \\ GHULAM KADIR AHMAD PARVEEZ*
}

\begin{abstract}
Transformation vector construction is one of the important disciplines for plant genetic transformation studies. A series of vector consisting of hygromycin phosphotransferase (hpt) gene as the selective marker and green fluorescent protein (GFP) as the visual reporter gene, under the control of double cauliflower mosaic virus 35S (2XCaMV35S) promoter has been engineered for transformation into oil palm cells. These genes were cloned into different types of cloning and expression vectors. The cloning was carried out by using restriction enzyme digestion and ligation method. Five intermediate vectors have been created for insertion of 2XCaMV35S-HPT-35ST and 2XCaMV35S-GFP-35ST into modified pBINPLUS backbone vector for particle bombardment and Agrobacterium-based transformation protocols. All vectors were sequenced to confirm the integrity of DNA region. The vectors were later transformed into oil palm embryogenic calli using biolistic device. The viability of the vectors was initially evaluated by transient GFP fluorescence expression observed under fluorescence microscope. It was demonstrated that the 2XCaMV35S promoter was able to drive the expression of gfp as gene in oil palm calli.
\end{abstract}

Keywords: vector construction, hygromycin, biolistic, embryogenic calli, GFP fluorescence.

Date received: 1 December 2016; Sent for revision: 6 December 2016; Received in final form: 9 February 2017; Accepted: 20 April 2017.

\section{INTRODUCTION}

Malaysia is one of the largest producers and exporters of palm oil and palm oil products in the world. This requires the palm oil industry to tackle the challenges in meeting the growing worldwide demand for palm oil as food, biodiesel and industrial non-food uses, such as oleochemicals. Improvement of oil palm crop by genetic engineering could have an important role to play in fulfilling the growing global need for oils and fats (Parveez et al., 2015a). Methods for the genetic engineering of oil palm will have to be developed in order to face future

Malaysian Palm Oil Board, 6 Persiaran Institusi,

Bandar Baru Bangi, 43000 Kajang,

Selangor, Malaysia.

E-mail: bahariah@mpob.gov.my challenges. Transformation of oil palm has been achieved by using particle bombardment (Parveez, 2000), Agrobacterium-mediated gene delivery (Masli et al., 2009) and DNA microinjection (Masani et al., 2014). However, such transformation approaches are still considered difficult due to the tissue culture processes which exhibit slow cell growth and low response under in vitro condition during the selection and regeneration of transgenic plants (Hashim et al., 2011; Masani et al., 2014). The transformation efficiencies previously recorded were rather low, between 0.7\%-1.0\% for Agrobacterium (Masli et al., 2009; Izawati et al., 2015) and 1.0\%-1.5\% for biolistic (Parveez, 2000; Parveez et al., 2015b).

In last 30 years, improvements of gene constructs involving the choice of genes such as promoters, selectable markers and backbone vectors have been intensively studied. Most studies 
were started by comparing the strength of different promoters to transcribe the selectable marker gene in different tissues of specific plants. For oil palm, several promoters have been identified to drive the reporter genes at high expression levels, specifically the 355 promoter of cauliflower mosaic virus (CaMV) and the maize ubiquitin promoter (Ubi1). Both promoters are constitutive promoters which have been characterised to deliver high transient gene expression in oil palm cells (Chowdhury et al., 1997; Masura et al., 2010). However, there has been no comparison between these promoters in the production of stably transformed oil palm cells.

Effective selection is an absolute requirement for successful transformation and regeneration of stable transgenic oil palm (Parveez et al., 2015a). Selection process requires suitable selection agents such as herbicide and antibiotic supplemented in selection media, allowing transformed cells to grow without any deleterious effects. A number of selectable marker genes have been tested for oil palm transformation, but the phosphinothricin acetyltransferase gene of Streptomyces hygroscopicus (bar) which confers resistance to the herbicide BASTA has been the most commonly used in oil palm transformation (Parveez, 2000; Masli et al., 2009; Nurfahisza et al., 2014; Parveez et al., 2015b). The bar gene has also been shown as a suitable selection agent for other monocot plants such as wheat (Melchiorre et al., 2002), maize (Chen et al., 2008), rice (Zhao et al., 2011) and turfgrass (Song et al., 2013). While, the hygromycin phosphotransferase gene $(h p t)$ of $E$. coli which confers resistance to hygromycin was also found to be the most efficient selection agent for oil palm transformation (Parveez et al., 1996). However, no report was published on production of stable transgenic oil palm using hygromycin as selection agent. Even though a few studies demonstrated regeneration of transgenic oil palm but no evidence of stable expression of transgenes has been achieved (Abdullah et al., 2005; Bhore and Shah, 2012). Nevertheless, the hygromycin antibiotic has been successfully used to obtain stable transgenic plants for legume, petunia, zoysia grass, finger millet and rice (Rosellini, 2012).

The ultimate goal of this study is to improve the genetic transformation and selection efficiency in oil palm. Efforts have been initiated to investigate the potential use of the $h p t$ gene as the selectable marker in the production of stable oil palm transformation. We also focused our effort to evaluate the potential use of double cauliflower mosaic virus $35 \mathrm{~S}$ (2XCaMV35S) promoter to control the hpt gene and reporter gene, i.e. green fluorescent protein $(g f p)$ for improved expression in oil palm. The transgene expression regulated by 2XCaMV35S promoter has been demonstrated to be highly active in most tissues including roots, mature leaves and shoots. The promoter has been used for the production of stable transgenic plants such as grape (Li et al., 2001), citrus (Benyon et al., 2013), soyabean (Paz et al., 2004), rice (Zheng et al., 2009) and maize (Reyes et al., 2010).

In this article, a vector carrying the hpt gene as the selectable marker and $g f p$ as the visual reporter gene, under the control of double cauliflower mosaic virus $35 S$ (2XCaMV35S) promoter was successfully constructed with the aim to increase the level of transgene expression and transformation efficiencies in oil palm. The suitability of the new vector to be used for oil palm transformation was verified.

\section{MATERIALS AND METHODS}

\section{DNA Manipulation}

DNA work was carried out according to standard protocols (Sambrook et al., 1989). NucleoSpin ${ }^{\circledR}$ Gel Extraction kit (Macherey-Nagel, Germany) was used to isolate specific restriction and polymerase chain reaction (PCR) fragments from agarose gels. DNA ligation was carried out according to the manufacturer's instructions (Promega). Transformation of DNA into competent E. coli strain $\mathrm{DH} 5 \alpha$ was carried out according to standard protocols.

\section{Polymerase Chain Reaction (PCR) Amplification}

PCR was carried out using PTC- $100^{\mathrm{TM}}$ Programmable Thermal Controller or PTC- $200^{\mathrm{TM}}$ Programmable Thermal Controller (MJ Research, Inc.). Amplifications were carried out in $25 \mu \mathrm{l}$ reaction mixture consisted of $1 \times \mathrm{PCR}$ buffer, $200 \mu \mathrm{M}$ dNTPs, appropriate primers and $10 \mathrm{ng}$ of plasmid DNA as template. Each PCR reaction was electrophoresed on $1 \%$ agarose gel at $110 \mathrm{~V}$ for $110 \mathrm{~min}$. The image of the ethidium bromide fluorescence of each amplified band was captured by the CCD camera system under UV irradiation.

\section{Vector Construction}

Three plasmid vectors, pTF101.1 (Paz et al., 2004) containing bar gene driven by the 2 XCaMV35S promoter, pCAMBIA 1303 (CSIRO, Australia) containing hpt gene and gusA-mgfp5-His6 reporter gene driven by CaMV35S promoter, pAMCFDV (Masani et al., 2014) containing $m g f p$ gene driven by the CFDV promoter, were used as DNA template for PCR amplification. The backbone vector used for the insertion of DNA fragment of promoter-gene of interest-terminator is pBINPLUS/ARS/Fse1, a modified vector from pBINPLUS/ARS (Belknap et al., 2008). Meanwhile, PCRII-TOPO (Invitrogen) and pGreenII000 (Hellens et al., 2000) were used as cloning vectors for construction of intermediate 
vectors. Overall cloning strategy for the vector construction is shown in Figure 1.

\section{Plant Material}

Oil palm embryogenic callus cultures derived from an E. guineensis var. tenera was used in this

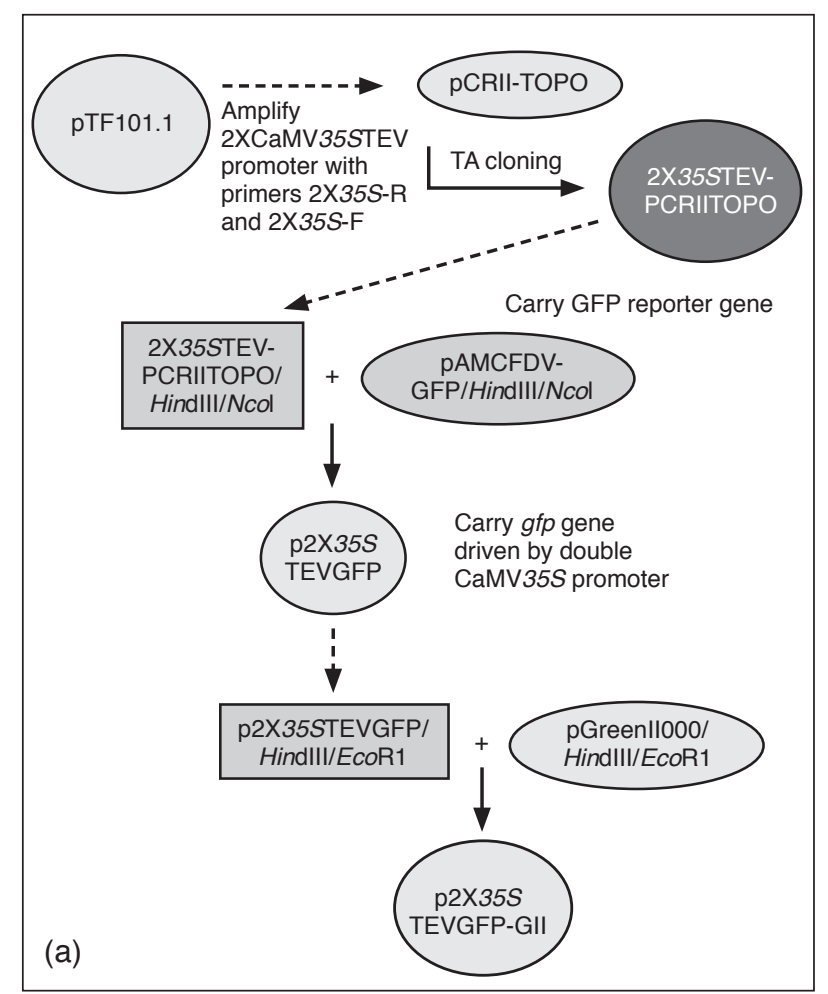

study. The $0.5 \mathrm{~g}$ fresh weights of embryogenic calli cultured on EC agar-solidified media containing MS macro and micronutrients (Murashige and Skoog, 1962) supplemented with $1 \mathrm{mg} /$ napthalene acetic acid (NAA) and $30 \mathrm{~g}^{\text {litre }}{ }^{-1}$ sucrose (Parveez and Christou, 1998) were used and arranged in the centre of a Petri dish prior to bombardment. The

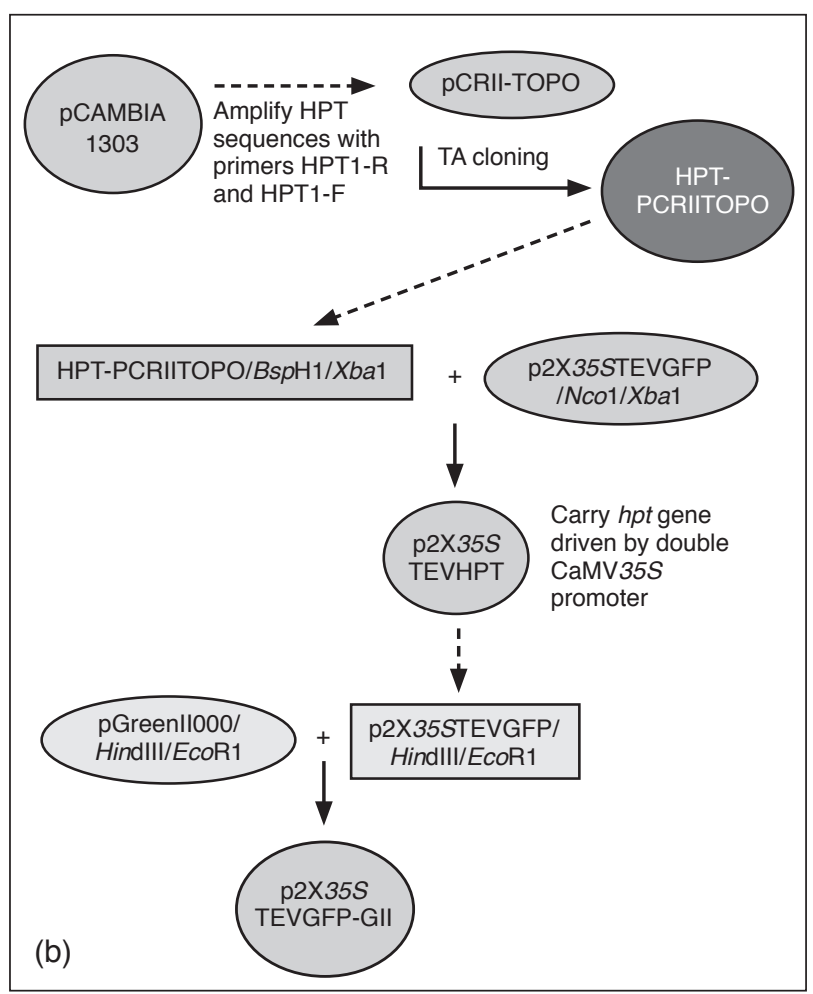

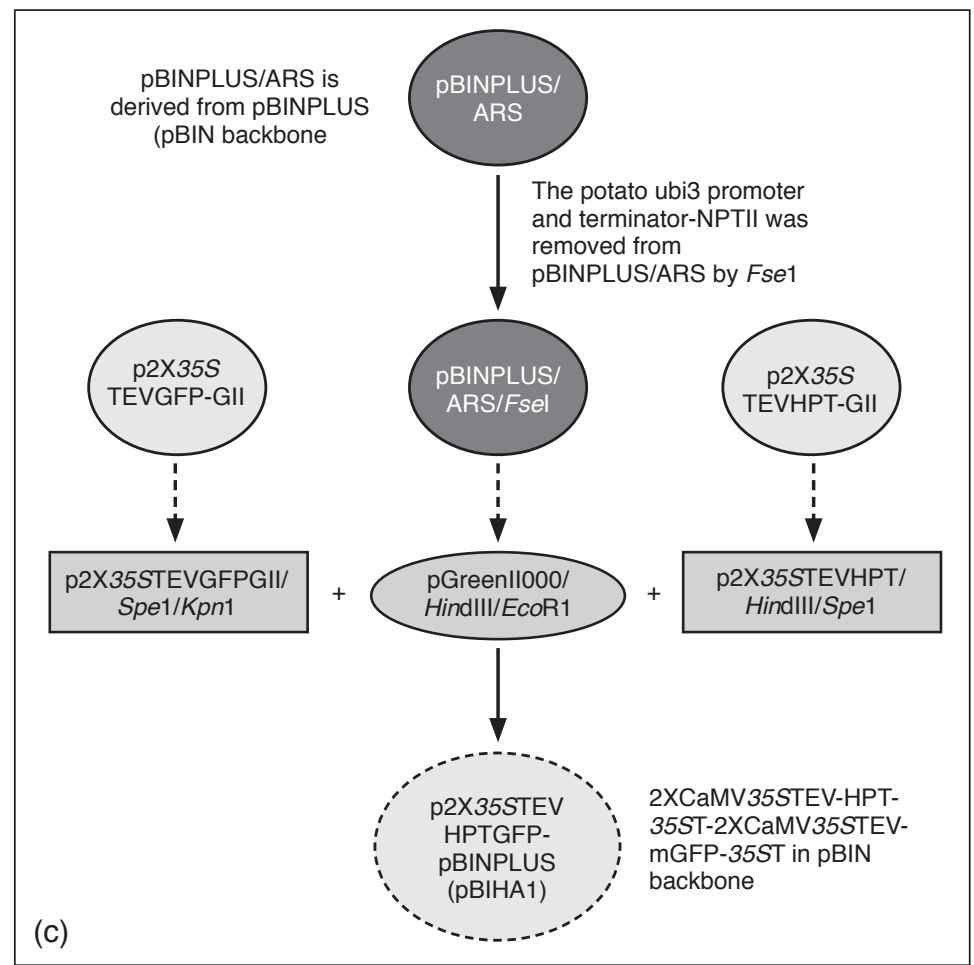

Figure 1. Cloning strategies of the 2X35S-TEVHPT-35ST (a) and 2X35S-mGFP-35ST (b) in pBINPLUS/ARS backbone to create pBIHA1 (c). Plus symbol (+) indicates the ligation of digested DNA fragments (represented by squares) to corresponding vectors restricted with appropriate restriction enzymes (represented by oval). Arrows shows the vectors resulted from the ligation (represented by circles). 
bombarded embryogenic calli were incubated in the dark at $28^{\circ} \mathrm{C}$ and continuously sub-cultured onto fresh EC medium every month.

\section{Biolistic Transformation of Oil Palm Calli}

The plasmid DNA was precipitated onto gold according the instruction manual for the Biolistic PDS-1000/He (BioRad) device. To each aliquot of $100 \mu \mathrm{l}$ gold particles, $20 \mu \mathrm{g}$ DNA, $100 \mu \mathrm{l} 2.5 \mathrm{M}$ $\mathrm{CaCl}_{2}$, and $40 \mu \mathrm{l} 0.1 \mathrm{M}$ spermidine were added in and vortexed vigorously for $3 \mathrm{~min}$ followed by centrifugation at $10000 \mathrm{rpm}$ for $10 \mathrm{~s}$. The supernatant was removed as much as possible and the pellet used was washed twice with $500 \mu \mathrm{l} 100 \%$ ethanol, mixed and centrifuged at $10000 \mathrm{rpm}$ for $60 \mathrm{~s}$. Finally, the DNA coated gold particles were resuspended in $120 \mu \mathrm{l} 100 \%$ ethanol. For each bombardment, about $6 \mu \mathrm{l}$ of DNA coated gold particles was dispensed in the centre of a macrocarrier and dried under sterile condition and used immediately for particle bombardment. Embryogenic calli which were placed in the centre of solid medium were used as target tissues. Transformation was carried out under the following conditions; rupture disc pressure at $1100 \mathrm{psi}$, distance from rupture to macrocarrier and macrocarrier to stopping screen was at $6 \mathrm{~mm}$ and 11 $\mathrm{mm}, 75 \mathrm{~mm}$ distance from stopping plate to target tissue and $67.5 \mathrm{~mm} \mathrm{Hg}$ vacuum pressure (Parveez, 1998).

\section{Microscopic Detection of GFP}

Expression of the gfp gene was examined in bombarded of oil palm embryogenic calli. Five replications were carried out and two controls were also incorporated; tissues without bombardment and bombardment using microcarriers without DNA. The bombarded tissues were then incubated at $28^{\circ} \mathrm{C}$ in the dark prior to GFP transient expression evaluation. Visualisation of GFP fluorescence on bombarded oil palm calli was carried out at several time intervals; $24 \mathrm{hr}$ after the bombardment followed by five and seven days. Images of GFPexpressing cells were captured using a Fluorescence Microscope Multizoom AZ-100 (Nikon) with a GFP specific filter.

\section{RESULTS AND DISCUSSION}

\section{Construction of Transformation Vectors}

A vector designated as pBIHA1, carrying the hygromycin phosphotransferase (hpt) gene as the selectable marker and a modified $g f p(\mathrm{~m} g f p)$ as the visual reporter gene, each was under the control of double cauliflower mosaic virus 35 S (2XCaMV35S) promoter, was successfully constructed by assembling hpt and mofp expression fragments in pBINPLUS/ARS/Fse1. In total, five intermediate vectors were constructed in order to produce the pBIHA1 vector (Table 1). All vectors were sequenced to confirm the integrity of DNA region.

The pBINPLUS/ARS/Fse1 backbone $(9.6 \mathrm{~kb})$ was modified from the binary plant transformation vector pBINPLUS/ARS (Figure 2a) that utilises the ubiquitin promoter and terminator sequences (Ubi3) to drive the nptII selectable marker gene. The modification was carried out by removing the potato ubi3 promoter-nptII-ubi3 terminator DNA fragment from pBINPLUS/aRS (12.4 kb) by Fse1 digestion, followed by self-ligation to produce pBINPLUS/ARS/FseI (Figure 2b). The pBINPLUS/

TABLE 1. LIST OF CONSTRUCTED VECTORS IN THIS STUDY

\begin{tabular}{|c|c|c|c|c|}
\hline No. & Ligation & Vectors & Size (bp) & Description \\
\hline 1 & PCR2X35STEV+PCRII TOPO & 2X35STEV-PCRII TOPO & 4894 & 2XCaMV35STEV-PCRII TOPO \\
\hline 2 & $\begin{array}{l}\text { pAMCFDV-GFP / HindIII / } \\
\text { NcoI +2X35STEV-PCRII TOPO/ } \\
\text { HindIII/ NcoI }\end{array}$ & p2X35STEVGFP & 4502 & 2XCaMV35STEV-mGFP-35ST \\
\hline 3 & PCRHPT1+PCRII TOPO & HPT- PCRII TOPO & 5013 & HPT-PCRII TOPO \\
\hline 4 & $\begin{array}{l}\text { HPT-PCRII TOPO / BspHI / XbaI } \\
+ \text { p2X35STEVGFP / NcoI / XbaI }\end{array}$ & p2X35STEVHPT & 4805 & 2XCaMV35STEV-HPT-35ST \\
\hline 5 & $\begin{array}{l}\text { pGII000 / HindIII / EcoRI + } \\
\text { p2X35STEVHPT / HindIII/ } \\
\text { EcoRI }\end{array}$ & p2X35STEVHPT-GII & 5462 & $\begin{array}{l}\text { 2XCaMV35STEV-HPT-35ST } \\
\text {-pGII000 }\end{array}$ \\
\hline 6 & $\begin{array}{l}\text { p2X35STEVGFP / HindIII/ } \\
\text { EcoRI + pGII000 / HindIII / EcoRI }\end{array}$ & p2X35STEVGFP-GII & 5159 & $\begin{array}{l}\text { 2XCaMV35STEV- } \\
\text { mGFP-35ST-pGII000 }\end{array}$ \\
\hline 7 & $\begin{array}{l}\text { p2X35STEVGFP / HindIII/ } \\
\text { SpeI + p2x35STEVGFP-GII / SpeI / } \\
\text { KpnI + pBINPLUS / ARS / FseI/ } \\
\text { HindIII / KpnI }\end{array}$ & $\begin{array}{l}\text { p2X35STEVHPTGFP- } \\
\text { pBINPLUS (pBIHA1) }\end{array}$ & 14194 & $\begin{array}{l}\text { 2XCaMV35STEV-HPT- } \\
\text { 35ST-2XCaMV35STEV- } \\
\text { mGFP-35ST-pBINPLUS }\end{array}$ \\
\hline 8 & pBINPLUS/ARS/FseI & pBINPLUS/ARS/FseI & 10082 & pBINPLUS/ARS/FseI \\
\hline
\end{tabular}

Note: 1-6: Intermediate vectors, 7: Final transformation vector and 8: Backbone vector. 
ARS/Fsel contains a unique Fse1 restriction site for the insertion of foreign gene sequences. Binary plant vector pBINPLUS/ARS was based on the pBINPLUS vector (Van Engelen et al., 1995), an improved vector derived from pBIN19 (Bevan, 1984). The pBINPLUS/ARS vector comprises a number of user friendly features such as two rare restriction sites (FseI) around the multiple cloning sites for easier subcloning of target genes. The vector replicates at high copy numbers in E. coli, leading to a high-yield DNA concentration for routine cloning procedure as well as for bombardment experiments. The pBINPLUS/ARS has been successfully used to introduce genes of interest into potato, tobacco, apple and tomato (Belknap et al., 2008).

In this study, 2XCaMV35S promoter was used as a driving promoter of $h p t$ and $m g f p$ genes with the aim to exhibit strong constitutive activity in oil palm tissues and subsequently result in efficient selection for stable transgenic oil palm. Higher expression also has been demonstrated in transgenic plants regulated by $2 \mathrm{XCaMV} 35 \mathrm{~S}$ promoter such as grape (Li et al., 2001) and citrus (Benyon et al., 2013). Constitutively transgene expression driven by this promoter also resulted in the production of stable transgenic plants for soyabean (Paz et al., 2004), strawberries (Qin et al., 2008), rice (Zheng et al., 2009), maize (Reyes et al., 2010) and citrus (Mondal et al., 2012). The DNA fragment of 2 X35S including TEV leader sequence, was amplified from pTF101.1 using the primers (restriction site underlined): $2 \mathrm{X} 35 \mathrm{~S}-\mathrm{F}$ (5'-GGAAGCTTCCTGCAGGTCAACATGGT-3') and 2X35S-R (5'-GGCCATGGTAGATCCCCCGTT
CG TAAAT-3'). A $0.9 \mathrm{~kb}$ 2X35STEV PCR product was cloned into PCRIITOPO $(3.9 \mathrm{~kb})$ vector to generate a $4.9 \mathrm{~kb} 2$ X35STEV-PCRIITOPO. The positive clones were selected and confirmed by restriction enzyme digestions and DNA sequencing. TEV leader sequence is non-encoding 5 '-end of Tobacco Etch Virus (TEV) sequence which has been shown to enhance the translation of genes in transgenic plants (Saunders and Lomonossoff, 2013). The TEV leader sequence has been shown to increase the transgene expression activity seven to 10 -fold compared to the expression of transgene without TEV leader sequence (Saunders and Lomonossoff, 2013).

The $0.9 \mathrm{~kb} 2 X 35 S T E V$ promoter fragment was extracted from plasmid 2X35STEV-PCRIITOPO and ligated to the HindIII and NcoI sites of pAMCFDVGFP (3.9 kb) to create p2X35STEVGFP $(4.5 \mathrm{~kb})$. The positive clones for $\mathrm{p} 2 \mathrm{X} 35$ STEVGFP were identified by HindIII and EcoR1 digestion which produced two DNA fragments of $1.9 \mathrm{~kb}$ 2X35STEV-GFP$35 S T$ and $2.6 \mathrm{~kb}$ pUC19 as shown in Figure $3 a$. The 2X35STEVGFP fragment was later inserted into the HindIII and EcoR1 sites of pGreenII0000 to generate a $5.2 \mathrm{~kb}$ p2X35STEVGFP-GII (Figure 1a) which was identified by digestion with HindIII and EcoR1 (Figure 3b). The p2X35STEVGFP-GII was constructed to introduce a unique restriction enzyme site for further cloning procedure. The cloning vector, pGreenII0000, is a mini binary vector that has the advantage of being relatively small $(3.3 \mathrm{~kb})$ for easy sub cloning procedure due to the presence of unique multiple cloning sites. The plasmid also replicates at high copy numbers in E. coli (Hellens et al., (a)

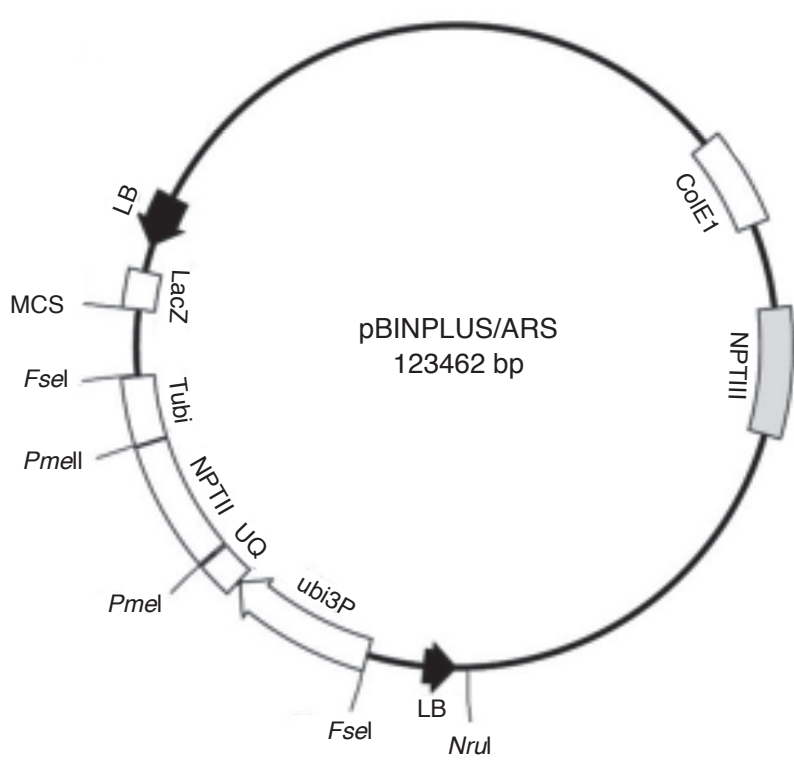

(b)

bp

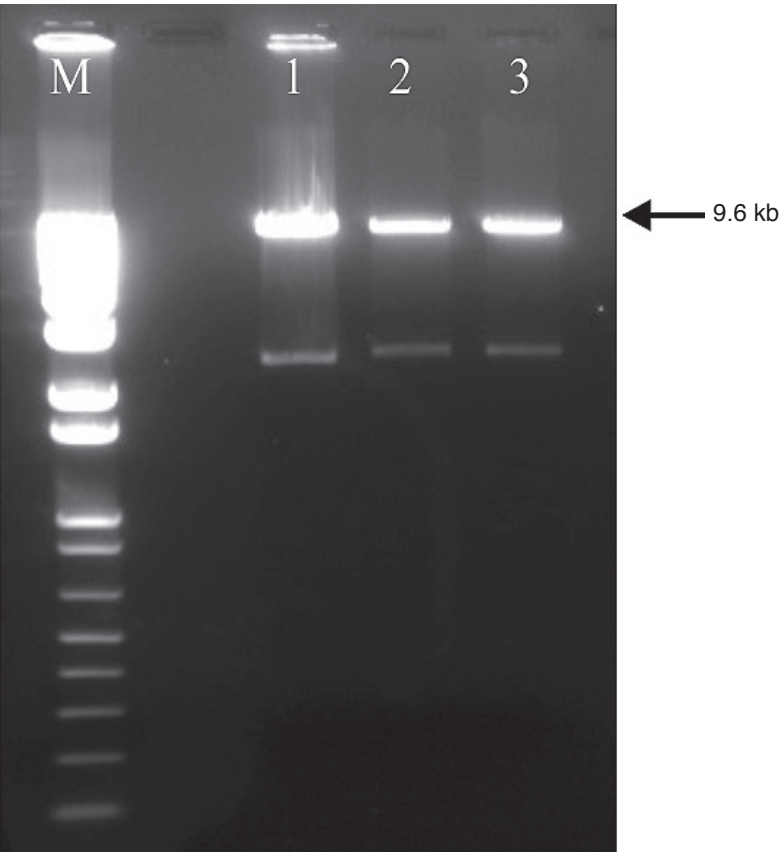

Figure 2. Construction of pBINPLUS/ARS/FseI by removing the potato ubi3 promoter-NPTII- ubi3 terminator DNA fragment from $p B I N P L U S / A R S$ (12.4 kb). (a) pBINPLUS/ARS; (b) lanes 1-3: purified plasmid DNA pBINPLUS/ARS was digested with Fse1. Lane M: 1 kb plus DNA ladder. Arrow indicates the size of fragment at $9.6 \mathrm{~kb}$. 
2000) making the plasmid DNA isolation is more convenient for identification of positive clones by restriction enzyme analysis.

In order to allow for selection of transformed oil palm tissues with the antibiotic hygromycin, the $h p t$ gene fragment was amplified from pCambia1303 using primers (restriction site underlined): HPT1-F (5'-GGTCATGAAAAAGCCTGACACCGCG-3') and HPT1-R (5'-GGCCTCTAGA CTATTTCTTTG CCCTCG GACG-3'). The $1.0 \mathrm{~kb}$ PCR product was gel purified and cloned into PCRIITOPO vector to produce HPT-PCRIITOPO $(5.0 \mathrm{~kb})$. Then, the HPT fragment was excised with BspHI and Xbal, gel purified and ligated into the $\mathrm{NcoI}$ and $\mathrm{Xba1}$ sites replacing the ofp gene of $\mathrm{p} 2 X 35 S T E V G F P$ to generate p2X35STEVHPT $(4.8 \mathrm{~kb})$. The positive clones for p2X35STEVHPT were confirmed by HindIII and EcoR1 digestion (Figure 3c). The 2X35STEVHPT was later digested with HindIII and EcoR1, gel purified and cloned into the similar sites of pGreenII0000 to generate a $5.5 \mathrm{~kb}$ of p2X35STEVHPT-GII (Figure 1b). Selection of positive clones for p2X35STEVHPTGII was carried out by HindIII and EcoR1 digestion which produced $2.2 \mathrm{~kb}$ 2X35STEV-HPT-35ST and $3.3 \mathrm{~kb}$ pGreenII000 DNA fragments (Figure 3d).

For construction of the final transformation vector (Figure 1c), a ligation procedure was performed using 3 DNA fragments in order to assemble the $1.9 \mathrm{~kb}$ 2X35STEVGFP and $2.2 \mathrm{~kb}$ 2X35STEVHPT in a single vector. The HindIII and Spe1 restricted 2X35STEVHPT DNA fragment of p2X35STEVHPT-GII and SpeI and KpnI restricted 2X35STEVGFP DNA fragment of p2X35STEVGFPGII were ligated to the HindIII and Kpn 1 sites of pBINPLUS / ARS / FseI to create p2X35STEVHPTGFPpBINPLUS $(\sim 14.2 \mathrm{~kb})$ designated as pBIHA1
(Figure 4). The p2X35STEVHPTGFP-pBINPLUS vector containing dual gene cassettes adjacent; the expression cassette with $g f p$ gene and selection cassette with hpt gene under the control of constitutive 2XCaMV35S promoter. This vector was designed in such a way for providing the potential for genomic integration of dual genes to be introduced into the plant tissues at a single locus. Subsequently, resulting in stable integration of the transgene at a transcriptionally active gene locus, which will be particularly useful for genetic engineering applications (Masani et al., 2009).

\section{Visualisation of GFP Expression}

The viability of vector pBIHA1 was evaluated in oil palm embryogenic calli via biolistic transformation. This was carried out to ensure that the construct carries an effective and functional $g f p$ gene. Even though $g f p$ gene expression was unstable in oil palm cells possibly due to toxicity (Parveez and Majid, 2008), the gene is still an attractive reporter gene for oil palm transformation as it is a non-destructive visual reporter marker that could be used to confirm the possibility of a successful transformation. Early evidence of successful transformation is very important since the selection process in oil palm transformation is laborious and time-consuming procedure. It was shown that putative transgenic oil palm embryoids could only be obtained after 6-10 months of culture. Longer time is needed for obtaining the transgenic shoots or plantlets when transformed calli were cultured on selection media (Parveez et al., 2015b; Izawati et al., 2015). In this study, the gfp expression cassette was placed next to hpt (a)

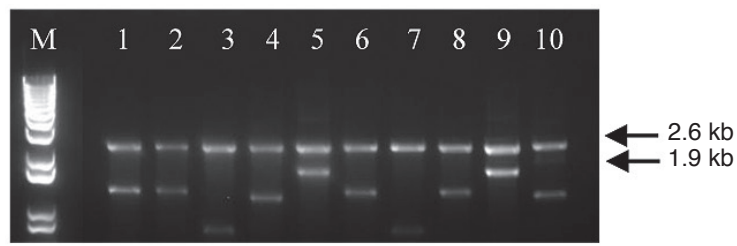

(b)

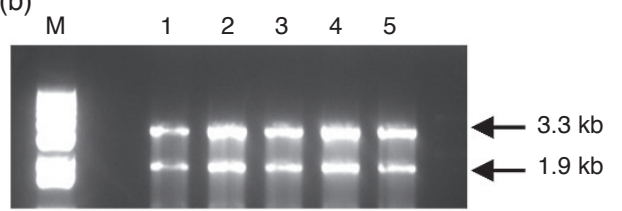

(c)

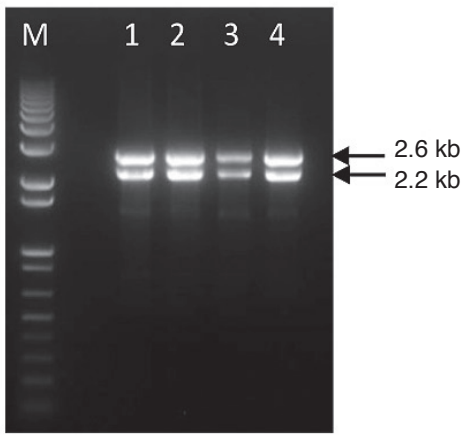

(d)

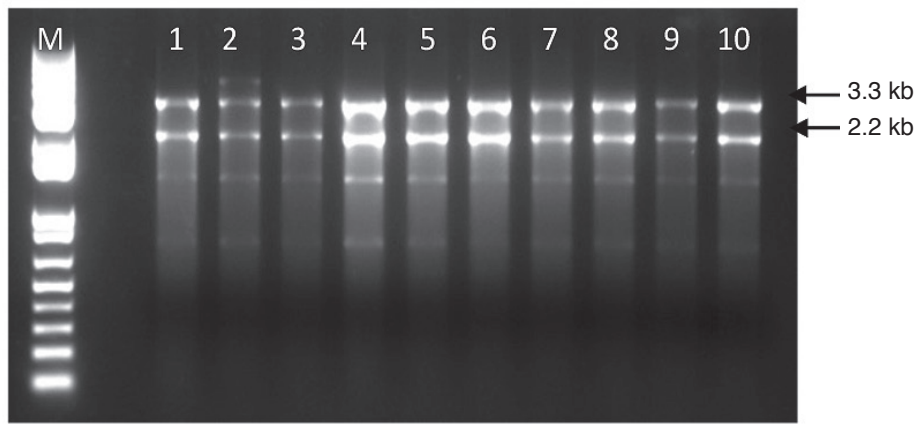

Figure 3. Screening of positive clones for intermediate vectors. Equal amount of DNA of each intermediate vector was digested with HindIII and EcoR1. Arrow indicates the size of the fragments produced for positive clones in each gel as predicted. Lane M: $1 \mathrm{~kb}$ plus DNA ladder. Restriction endonuclease analyses of (a) lanes 5 and 9: positive clones for p2X35STEVGFP; (b) lanes 1- 5: positive clones for p2X35STEVGFP-GII; (c) lanes 1- 4: positive clones for 2 2X35STEVHPT and (d) lanes 1- 10: positive clones for p2X35STEVHPT-GII. 
expression cassette for confirmation of transgene delivery and determination of transformation efficiency. Result showed that the bombarded oil palm calli produced visible GFP spots as early as $24 \mathrm{hr}$ post-bombardment, and reached a peak of more than 30 spots per tissue clump in five to seven days post-bombardment (Figures $5 a$ and $5 b$ ). No GFP activity was observed in control tissues (Figure $5 c)$. The results clearly suggested that the construct was successfully transferred into the oil palm cells and the $g f p$ reporter gene within the construct was functional.

\section{CONCLUSION}

A new vector designed as pBIHA1 carrying the hpt and $g f p$ genes driven by the double cauliflower mosaic virus $35 S$ is currently available to be used in both biolistic and Agrobacterium-

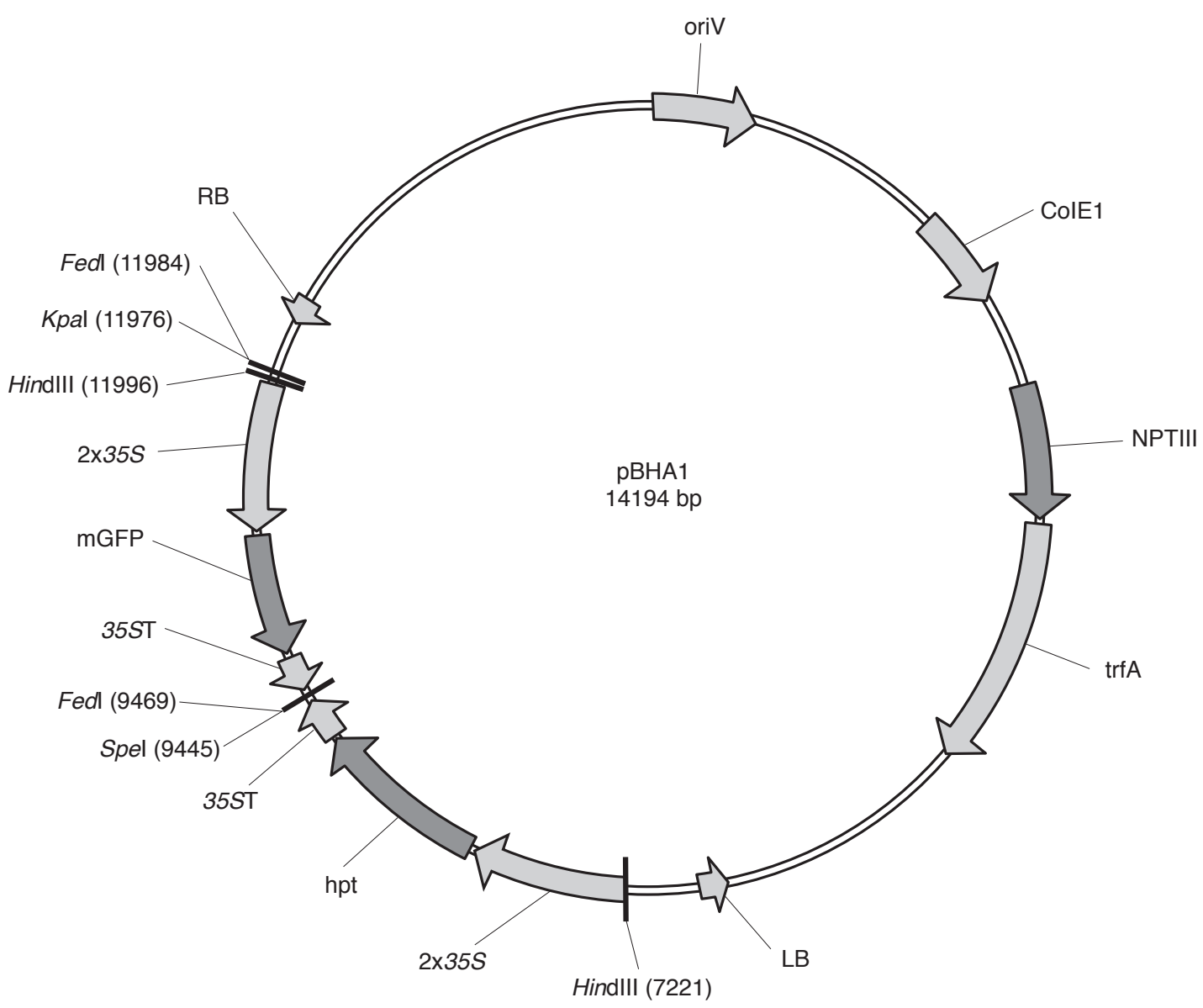

Figure 4. Restriction map of pBIHA1 vector. The restriction sites and the number of each site show the position in the vector. The arrow shows the orientation of each of DNA fragments assembled. LB: left border of T-DNA; 2X35S: double cauliflower mosaic virus 35S promoter; hpt: gene for hygromycin phosphotranferase; mGFP: modified green fluorescent protein; 35ST: 35S terminator gene and RB: right border of T-DNA.
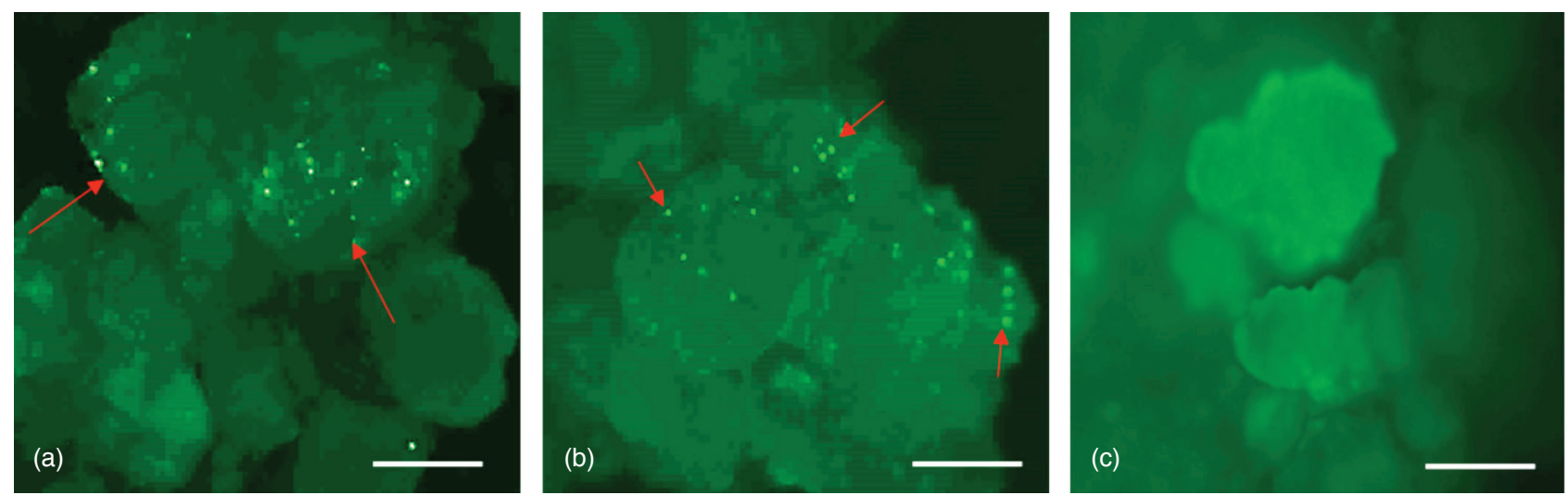

Figure 5. Visualisation of $m$ GFP fluorescence in bombarded oil palm embryogenic calli with $p B I H A 1$ vector. $a, b: 24$ hr after bombardment and c: non-bombarded embryogenic calli as control. Red arrows indicate GFP spots and scale bar equals $300 \mathrm{um}$. 
based transformation protocols for oil palm. Further research will continue to investigate the regeneration rate of pBIHA1 transformed calli cultured on hygromycin selection media towards developing an efficient oil palm transformation system. In addition, the stable integration of the gene into the cells of oil palm plants will later be verified by PCR and Southern blot analyses to further confirm the integration and copy number of the transferred gene, respectively. In the future, we expect that this vector will make it possible to carry and transfer a gene that will improve the value of oil palm varieties.

\section{ACKNOWLEDGEMENT}

The authors would like to thank the Director-General of MPOB for permission to publish this article and Dr R W Bellnap (USDA Agricultural Research Services) for the supply of pBINPLUS/ARS vector use in this study. We also would like to acknowledge all members of the Transgenic Technology Group of MPOB for their assistance.

\section{REFERENCES}

ABDULLAH, R; ZAINAL, A; HENG, W Y; Li, L C; BENG, Y C; PHING, L M; SIRAJUDDIN, S A; PING, W Y S and JOSEPH, J L (2005). Immature embryo: a useful tool for oil palm (Elaeis guineensis Jacq.) genetic transformation studies. Electronic. J. Biotechnol, 18: 24-34.

BELKNAP, R W; ROCKHOLD, R D and MCCUE, K F (2008). pBINPLUS/ARS: an improved plant transformation vector based on pBINPLUS. BioTechniques, 44: 753-756.

BEVAN, M (1984). Binary Agrobacterium vectors for plant transformation. Nucleic Acids Res., 12: 87118721.

BENYON, L S; STOVER, E; BOWMAN, K D; NIEDZ, R; SHATTERS, R G and ZALE, J (2013). GUS expression driven by constitutive and phloemspecific promoters in citrus hybrid US-802. In vitro Cell Dev. Biol. Plant, 49: 255-265.

BHORE, S J and SHAH, F H (2012). Genetic transformation of the American oil palm (Elaeis oleifera) immature zygotic embryos with antisense palmitoyl-acyl carrier protein thioesterase (PATE) gene. World Appl. Sci. J., 16: 362-369.

CHEN, R; XUE, G; CHEN, P; YAO, B; YANG, W and MA, Q (2008). Transgenic maize plants expressing a fungal phytase gene. Transgenic Res., 17: 633-643. DOI: 10.1007 / s11248-007-9138-3.

CHOWDHURY, M K U; PARVEEZ, G K A and SALEH, NM (1997). Evaluation of five promoters for use in transformation of oil palm (Elaeis guineensis Jacq). Plant Cell Rep., 16: 277-281.

HASHIM, A T; ISHAK, Z; OOI, S E; ROSLI, S K; CHAN, P L and ROHANI, O (2011). Forging ahead with clones. Further Advances in Oil Palm Research (Mohd Basri Wahid; Choo, M Y and Chan, K W eds.). MPOB, Bangi. p. 102-140.

HELLENS, R P; EDWARDS, E A; LEYLAND, N R; BEAN, S and MULLINEAUX, P M (2000). pGreen: a versatile and flexible binary $\mathrm{Ti}$ vector for Agrobacterium-mediated plant transformation. Plant Molecular Biology Vol. 42 No. 6: 819-832.

IZAWATI, A M D; MASANI, M Y A; ISMANIZAN, I and PARVEEZ, G K A (2015). Evaluation on the effectiveness of 2-deoxyglucose-6-phosphate phosphatase (DOGR1) gene as a selectable marker for oil palm (Elaeis guineensis Jacq.) embryogenic calli transformation mediated by Agrobacterium tumefaciens. Front. Plant Sci., 6: 727. DOI:10.3389/ fpls.2015. 00727.

LI, Z; JAYASANKAR, S and GRAY, D J (2001). Expression of a bifunctional green fluorescent protein (GFP) fusion marker under the control of three constitutive promoters and enhanced derivatives in transgenic grape (Vitis vinifera). Plant Science, 160: 877-887.

MASANI, M Y A; PARVEEZ, G K A; IZAWATI, A M D; LAN, C P and AKMAR, SNA (2009). Construction of PHB and PHBV multiple-gene vectors driven by an oil palm leaf-specific promoter. Plasmid, 3: 191200.

MASANI, M Y A; NOLL, G A; PARVEEZ, G K A; SAMBANTHAMURTHI, R and PRÜFER, D (2014). Efficient transformation of oil palm protoplasts by PEG-mediated transfection and DNAmicroinjection. PLoS One, 9(5): e96831.

MASLI, D I A; PARVEEZ, G $\mathrm{K}$ A and YUNUS, A M M (2009). Transformation of oil palm using Agrobacterium tumefaciens. J. Oil Palm Res. Vol. 21: 643-652.

MASURA, S S; PARVEEZ, G K A and ISMANIZAN, I (2010). Isolation and characterization of oil palm constitutive promoter derived from ubiquitin extension protein (Uep1) gene. New Biotechnol J., 27: 289-299. 
MELCHIORRE, M N; LASCANO, H R and TRIPPI, V S (2002). Transgenic wheat plants resistant to herbicide Basta obtained by microprojectile bombardment. Biocell, 26: 217-223.

MONDAL, S; DUTT, M; GROSSER, J and DEWDNEY, M (2012). Transgenic citrus expressing the antimicrobial gene Attacin E (attE) reduces the susceptibility of 'Duncan' grapefruit to the citrus scab caused by Elsinoë fawcettii. Eur J Plant Pathol., 133: 391-404.

MURASHIGE, T and SKOOG, F (1962). A revised medium for rapid growth and bioassays with tobacco tissue cultures. Physiol. Plant., 15: 473-497.

NURFAHISZA, A R; RAFIQAH, M A; MASANI, M Y A; NOR HANIN, A A; RASID, O A; PARVEEZ, G $\mathrm{K} A$ and ISMANIZAN, I (2014). Molecular analysis of transgenic oil palm to detect the presence of transgenes. J. Oil Palm Res. Vol. 26: 73-80.

PARVEEZ, G K A; CHOWDHURY, M K U and SALEH, N M (1996). Determination of minimal inhibitory concentration of selection agents for oil palm (Elaeis guineensis Jacq.) transformation. Asia Pacific J. Molecular Biology and Biotechnology, 4: 219228.

PARVEEZ, G K A (1998). Optimization of Parameters Involved in the Transformation of Oil Palm Using the Biolistics Method. Ph.D thesis, Universiti Putra Malaysia.

PARVEEZ, G K A and CHRISTOU, P (1998). Biolisticmediated DNA delivery and isolation of transgenic oil palm (Elaeis guineensis Jacq.) embryogenic callus cultures. J. Oil Palm Res. Vol. 10: 29-38.

PARVEEZ, G K A (2000). Production of transgenic oil palm (Elaeis guineensis Jacq.) using biolistic techniques. In Molecular Biology of Woody Plants (Jain, S M and Minocha, S C eds.). Kluwer Academic Publishers. p. 27-350.

PARVEEZ, G K A and MAJID, N A (2008). Factors affecting green fluorescence protein (GFP) gene expression in oil palm after microprojectile bombardment mediated transformation. J. Oil Palm Res. Vol. 20: 495-507.

PARVEEZ, G K A; RASID, O A; MASANI, M Y A and SAMBANTHAMURTHI, R (2015a). Biotechnology of oil palm: strategies towards manipulation of lipid content and composition. Plant Cell Rep., 34: 533-543.

PARVEEZ, G K A; BAHARIAH, B; AYUB, N H; MASANI, M Y A; RASID, O A; TARMIZI, A $\mathrm{H}$ and ISHAK, Z (2015b). Production of polyhydroxybutyrate in oil palm (Elaeis guineensis Jacq.) mediated by microprojectile bombardment of PHB biosynthesis genes into embryogenic calli. Front. Plant Sci., 6: 598. DOI: 10.3389 / fpls.2015.00598

PAZ, M M; SHOU, H X; GUO, Z B; ZHANG, Z Y; BANERJEE, A K and WANG, K (2004). Assessment of conditions affecting Agrobacterium-mediated soybean transformation using the cotyledonary node explant. Euphytica, 136 (2): 167-179.

QIN, Y; TEIXEIRA, D S J; ZHANG, L and ZHANG, $S$ (2008). Transgenic strawberry: state of the art for improved traits. Biotechnol Adv., 26: 219-232.

REYES, F C; SUN, B; GUO, H; GRUIS, D F and OTEGUI, M S (2010). Agrobacterium tumefaciensmediated transformation of maize endosperm as a tool to study endosperm cell biology. Plant Physiol., 153: 624-631.

ROSELLINI, D (2012). Selectable markers and reporter genes: a well furnished toolbox for plant science and genetic engineering. Cri. Rev. Plant Sci., 31(5): 401-453.

SAMBROOK, J; FRITSCH, E F and MANIATIS, T (1989). Molecular Cloning: A Laboratory Manual. $2^{\text {nd }}$ edn. Cold Spring Harbor, NY.

SAUNDERS, K and LOMONOSSOFF, G P (2013). Exploiting plant virus-derived components to achieve in planta expression and for templates for synthetic biology applications. New Phytol., 200: 1626.

SONG, I J; BAE, T W; GANESAN, M; KIM, J I; LEE, H Y and SONG, P S (2013). Transgenic herbicideresistant turfgrasses. Herbicides - Current Research and Case Studies in Use (Price, A J and Kelton, J A eds.). DOI: 10.5772 / 56096.

VAN ENGELEN, F A; MOLTHOFF, J W; CONNER, A J; NAP, J P; PEREIRA, A and STIEKEMA, W J (1995). pBINPLUS - an improved plant transformation vector based on pBIN19. Transgenic Res., 4: 288-290.

ZHAO, Y; GUO, L; WANG, H and HUANG, D (2011). Integration and expression stability of transgenes in hybriding transmission of transgenic rice plants produced by particle bombardment. Mol. Plant Breed., 2: 48-59.

ZHENG, Y; HE, X W; YING, Y H; LU, J F; GELVIN, $S$ B and SHOU, H X (2009). Expression of the Arabidopsis thaliana histone gene AtHTA1 enhances rice transformation efficiency. Mol. Plant, 2(4): 832837. 